\title{
Modeling and Simulation of Thermally-Induced Static Stress on A Heat Exchanger
}

\author{
${ }^{1}$ Agberegha, Orobome Larry and ${ }^{2}$ Godspower Edafeadhe \\ ${ }^{1}$ Department of Mechanical Engineering \\ Federal University of Petroleum Resources, Effurun, Nigeria. \\ ${ }^{2}$ Department of Mechanical Engineering Delta State Polytechnics \\ Otefe- Oghara, Nigeria.
}

\begin{abstract}
The ultimate purpose of any stress analysis is to allow the comparison of the developed stresses, strains, and deflections with those that are allowed by the design criteria. Heat exchanger is a thermo-fluid machine used to transfer heat between two or more fluids. Depending on the goal for which the designer intends to achieve, heat exchangers, therefore, could be used for both heating and cooling processes. This work is about Static Stress analysis to determine or estimate the stresses, displacements, strains, including the factor of safety of the Heat Exchanger (HE) and its designed carrying or working capacity. This analysis predict failure by evaluating whether or not the Heat Exchanger will be able to withstand the internal stresses due to its maximum loading and working capacity. The summation of the masses of individual component inside the shell and tube heat exchanger was generated by the material library in the software using the provided model geometry and the resultant data was used to run the simulation. The maximum Stress experienced by the Heat Exchanger according to the simulation result is $1.254 \mathrm{e}-01 \mathrm{~N} / \mathrm{mm}^{2}$ (MPa) which is far less than the yield strength of the material used in building it $\left(1.72369 \mathrm{e}+08 \mathrm{~N} / \mathrm{m}^{2}\right)$. Hence the Heat Exchanger will survive the maximum loading and working capacity according to von Mises Stress analysis and with a significant factor of safety. For the numerical simulation and analysis of heat exchanger, the static stress processes is successfully captured. The simulations suggest that a critical stress level may exist beyond which a minor disturbance can induce a catastrophic damage.
\end{abstract}

\subsection{Introduction:}

Stress analysis is specifically concerned with solid objects. Stress analysis adopts the macroscopic view of materials characteristic of continuum mechanics, namely that all properties of materials are homogeneous at small enough scales. Thus, even the smallest particle considered in stress analysis still contains an enormous number of atoms, and its properties are averages of the properties of those atoms. In stress analysis, one normally disregards the physical causes of forces or the precise nature of the materials. Instead, one assumes that the stresses are related to strain of the material by known constitutive equations [22]. By the Newton's third law of motion, any external forces that act on a system must be balanced by internal reaction forces [23] or cause the particles in the affected part to accelerate. In a solid object, all particles must move substantially in concert in order to maintain the object's overall shape [22], therefore, the 'external force' acting on the heat exchanger is taken to be the fluid while the 'internal reaction' is the thermally induced static stress.

The final purpose of any stress analysis is to allow the comparison of the developed stresses, strains and deviations with those allowed by the design criteria. Obviously, all structures, and their components, must be designed to have a capacity greater than what is expected to develop during the use of the structure to avoid failures. The tension calculated to develop in a member is compared to the strength of the material with which the composition is manufactured by calculating the ratio between the strength of the material and the calculated resistance. The ratio must obviously be greater than 1.0 if the member should not fail. However, the relationship between the allowable voltage and the developed voltage must be greater than 1.0 as a factor of safety (design factor) will be specified in the design requirement of the structure. All structures are designed to overcome the load that these structures are expected to experience during their use. The design factor (a number greater than 1.0) represents the degree of uncertainty in the value of the loads, the strength of the material and the consequences of the failure. The tension (or load, or deflection) that the structure is expected to experience is known as the work, the design or the limit voltage. The limit voltage, for 
example, is chosen to be a fraction of the elastic resistance of the material from which the structure is made. The relationship between the final material strength and the admissible voltage is defined as the safety factor against the final failure [22].

Conversely, Heat exchanger is a thermo-fluid machine used to transfer heat between two or more fluids. Heat exchangers are heat sinks, acting as fluid temperature regulators. Heat exchangers are devices that regulate efficient heat transfer from one fluid to another [10]. Heat exchangers are devices used to transfer energy between two fluids at different temperatures. They improve energy efficiency, because the energy already within the system can be transferred to another part of the process, instead of just being pumped out and wasted. In the new era of sustainability, the growing urgency to save energy and reduce overall environmental impacts has placed greater emphasis on the use of heat exchangers with better thermal efficiency. In this new scenario, the plate heat exchanger can play an important role [14]. Depending on the goal for which the designer intends to achieve, Heat exchangers, therefore, could be used for both heating and cooling processes. It could be inferred that every material acts as a heat exchanger, directly or indirectly. Any material that mediates the transfer of heat between two or more fluids is a heat exchanger. Applications of heat exchangers abound: they are used in space heating, refrigeration, air conditioning, power stations, chemical plants, petrochemical plants, petroleum refineries, natural-gas processing, and sewage treatment, internal combustion engine in which a circulating fluid known as engine coolant flows through radiator coils and air flows past the coils, which cools the coolant and heats the incoming air, the heat sink, which is a passive heat exchanger that transfers the heat generated by an electronic or a mechanical device to a fluid medium, often air or a liquid coolant, nuclear plants [2]. The human as wells animal and fishes' body could be a heat exchanger as it regulates the body temperature, using fluids and other parts of the body.

Nowadays the growing prices of fossil fuel and strict environment regulations seriously force industrial clusters to improve processing plants' energy efficiency as much as possible. Therefore, industrial energy systems, like heat exchanger networks, cooling water systems, rankine cycles and so on, have attracted high attentions from both academic and industrial practices [8]. Among these energy systems in a processing plant, a heat exchanger network and a cooling water system are two major elements which have very close relationships to energy consumption [9]. Such two subjects have been widely and deeply studied in the past few years and various kinds of design approaches have been proposed with extensive application to industrial cases [7].

For optimal performance, heat exchangers are designed to maximize the surface area of the wall between the two fluids, while minimizing resistance to fluid flow through the exchanger. The efficiency of the exchanger can also be affected by the addition of fins or corrugations in one or both directions, which increases the area of the surface and can channel fluid flow or induce turbulence [2].

[1] Salimpour et. Alabama. (2018) carried out the Constructal design of multilayer microchannel heat sinks. In this work, adopting the concepts of constructive theory, a research is carried out to optimize the circular multilayer micro-channels embedded within a rectangular heat sink with different numbers of layers and flow configurations

The methodology adopted for this study is presented here [1]:

\subsection{Mathematical Modeling and Design Methodology}

For optimum performance, the heat exchangers are designed to maximize the area of the wall surface between the two fluids, while minimizing resistance to fluid flow through the exchanger. The performance of the exchanger can also be affected by the addition of fins or corrugations in one or both directions, which increases the area of the surface and can channel fluid flow or induce turbulence [2].

To simplify complex problems to simple ones so as to make analysis less cumbersome, Perry made the following assumptions as follows:

1. The heat exchanger is at steady state.

2. The specific heat of each stream remains constant throughout the exchanger.

3. The overall heat transfer coefficient is constant. $U$

4. All elements of a given fluid stream experience the same thermal history as they pass through the heat exchanger

5. Heat losses are negligible.

\subsection{Heat exchanger Design procedures}


For the Overall design procedure, the methodology adopted in the present work is [3]. All calculations start with an assumed design, which is then rated to determine its capacity. Suitable modifications are made to the assumed design in order to approach the required capacity and the final design [3]:

1. Determine suitable types of condensers.

2. Determine the heat load.

3. Select the coolant temperatures and calculate an overall logarithmic mean temperature difference.

4. Estimate an overall coefficient or by prior experience using estimated individual coefficients.

5. Calculate the area.

6. Select a tube size, pitch, and length and determine the number of tubes, shell size, and baffling, if required.

7. Steps 1 to 6 result in a guessed design. Three options are now available:

- (a) Go to a computer program and rate. A number of trials may be required to obtain a final design.

- (b) Make a preliminary hand calculation design by use of the approximate average condensing coefficient equations.

- (c) After step 7(b), proceed to use the stepwise calculations and equations or go to the computer programs for final checking. After doing step 7(b), the number of trials on the computer should be substantially less than in 7(a).

In the cause of operation of a heat exchanger, there may exist thermally-induced static stress leading to, may be, structural and wear issues. The objective of this paper is to model and analyse stress concentration, possible structural deformation and thermal gradient of the heat exchanger. Here the heat exchanger is designed by using CAD software. Also, transverse normal stresses are investigated. The heat exchanger was studied under combined thermo-mechanical loading.

Design procedures for heat exchangers are based on a series of correlations to estimate heat transfer coefficients, pressure drops, costs, etc. Each correlation is characterized by uncertainties, i.e. it returns an approximate value of the variable that it aims at predicting [6]. In this paper, we investigated how sensitive the evaluation of the total cost is to these uncertainties for shell and tube heat exchangers. A decomposition of variance approach was used to calculate the total effect of each uncertain variable. Three test cases are studied in which it was found that the most influential uncertainties are those related to the correlations to evaluate the purchase cost and the heat transfer coefficient of the roof side. The probability distributions of the total cost are presented and show a great variation of the total cost. The impact of the cost of energy was also investigated, which revealed that the uncertainty about the cost of energy had a smaller total effect than that of other variables. Sensitivity analysis of the heat exchanger was also carried out.

The network of heat exchangers and the cooling water system are two main elements of the energy systems in the processing plants. These two topics have a very close interaction with each other. However, most current research first synthesizes the network of heat exchangers and then designs the cooling water system. This sequential methodology probably omits optimal solutions and gives rise to some suboptimal designs from a general perspective [7]. To overcome this limitation of traditional methods, this document presents a simultaneous methodology to integrate the network of heat exchangers and the cooling water system as a complete system. Unlike conventional approaches, the methodology treats cooling water as a special cold stream whose mass flow, the initial and final temperatures are

all unknown variables and require to be optimized. The methodology mainly makes use of a modified stage-wise superstructure that covers most possible configurations for integrating heat exchanger network and cooling water system. The mathematical optimization model corresponding to the superstructure is a mixed integer nonlinear programming (MINLP) problem. The total annual cost (TAC) is set as the objective function composed by utility cost, pumping cost, and capital cost of cooling tower and heat exchanger. An industrial case study is used to demonstrate the capabilities of the proposed methodology [7].

$$
\begin{aligned}
& A=\frac{Q}{\left(U \Delta T_{m}\right)} \\
& \mathrm{Q}=\mathrm{m} \cdot \mathrm{cp} \cdot \mathrm{dT}
\end{aligned}
$$

$\mathrm{Q}=$ Amount of energy or heat $(\mathrm{kJ})(\mathrm{Btu}) ; \mathrm{m}=$ mass of the substance $(\mathrm{kg})(\mathrm{lb}) ; \mathrm{cp}=$ Specific thermal capacity of the substance $(\mathrm{kJ} /$ $\mathrm{kg} \mathrm{oC})$ or (Btu / (lb. F); dT = Increase in the temperature of the substance (oC) $\left({ }^{\circ} \mathrm{F}\right)$.

$$
\Delta T_{m}=\frac{\left(T_{1}-T_{2}\right)-\left(T_{2}-T_{1}\right)}{\ln \frac{\left(T_{1}-T_{2}\right)}{\left(T_{2}-T_{1}\right)}}
$$

$\mathrm{Q}=$ Amount of energy or heat $(\mathrm{kJ})(\mathrm{Btu}) ; \mathrm{m}=$ mass of the substance $(\mathrm{kg})(\mathrm{lb}) ; \mathrm{cp}=$ Specific thermal capacity of the substance $(\mathrm{kJ} /$ $\left.\mathrm{kg}{ }^{\circ} \mathrm{C}\right)$ or $\left(\mathrm{Btu} /(\mathrm{lb} . \mathrm{F})\right.$; dT $=$ Increase in the temperature of the substance $\left({ }^{\circ} \mathrm{C}\right)\left({ }^{\circ} \mathrm{F}\right)$. 
This section of heat exchanger design and analysis is carried out with the following assumptions:

Heat given up by the hot fluid, Q

$$
Q=m_{h} c_{p h}\left(t_{h 1}-t_{h 1}\right)
$$

Heat picked up by the cold fluid, Q

Total heat transfer rate in the heat exchanger,

$$
Q=Q=m_{c} c_{c h}\left(t_{c 1}-t_{c 1}\right)
$$

$$
Q=U A \theta_{m}
$$

Where $U$ is overall heat transfer coefficient between the two fluids

$A$ is the effective heat transfer area

$\theta_{m}$ is the appropriate mean value of temperature difference or logarithmic mean temperature

difference (LMTD).

$c_{p}$ is specific heat of fluid at constant pressure $\left[\mathrm{J} / \mathrm{kg}^{0} \mathrm{C}\right]$

\subsection{Pressure drop:}

In the design of heat exchangers, the considerations of pressure drop are usually very important. Normally, a design restriction could be $\Delta \mathrm{P} \leq \mathrm{N}$ psi, where the number $\mathrm{N}$ is specified, and such restrictions can be applied both on the tube side and on the shell side. The calculation of the pressure drop on the tube side is done by first estimating the friction factor (Darcy) for the flow through the tubes from the value of the Reynolds number and the relative roughness, and applying the viscosity correction that we discuss in class.

\subsection{Numerical simulation:}

Numerical simulation of heat exchanger remains a challenge due to the inherent difficulties in dynamic failure simulation [12]. Computer simulation is the reproduction of the behavior of a system that uses a computer to simulate the results of a mathematical model associated with that system. Since they allow verifying the reliability of the chosen mathematical models, computer simulations have become a useful tool for the mathematical modeling of many natural systems in physics (computational physics), astrophysics, climatology, chemistry, biology and manufacturing, human systems in economics, psychology, social sciences, healthcare and engineering. The simulation of a system is represented as the execution of the system model. It can be used to explore and obtain new knowledge about new technologies and to estimate the performance of systems that are too complex for analytical solutions [13]. With Flow Simulation it is possible to study a wide range of fluid flow and heat transfer phenomena that include the following: Internal and external fluid flows, Stationary and time-dependent fluid flows, Compressible fluid flows and incompressible gases, Subsonic, transonic, and supersonic gas flows, free, forced and mixed convection, fluid flows with boundary layers, including the effects of roughness of the walls, flows of laminar and turbulent fluids, multispecific fluids and solids of multiple components, flows of fluids in models with moving / rotating surfaces and / or parts, heat conduction in fluid, solid and porous media with / without conjugate heat transfer and / or resistance to contact heat between solids and / or heat transfer of radiation between opaque solids (some solids may be considered transparent to radiation), and / or heat sources of volume (or surface), for example Due to the Peltier effect, etc., Joule heating due to direct electric current in electric conduction solids1, various types of thermal conductivity in solid medium, ie, isotropic, unidirectional, biaxial / axisymmetric and orthotropic, Fluid flows and heat transfer in porous media, Non-Newtonian fluid flows, compressible liquid flows [18] to [21]. 


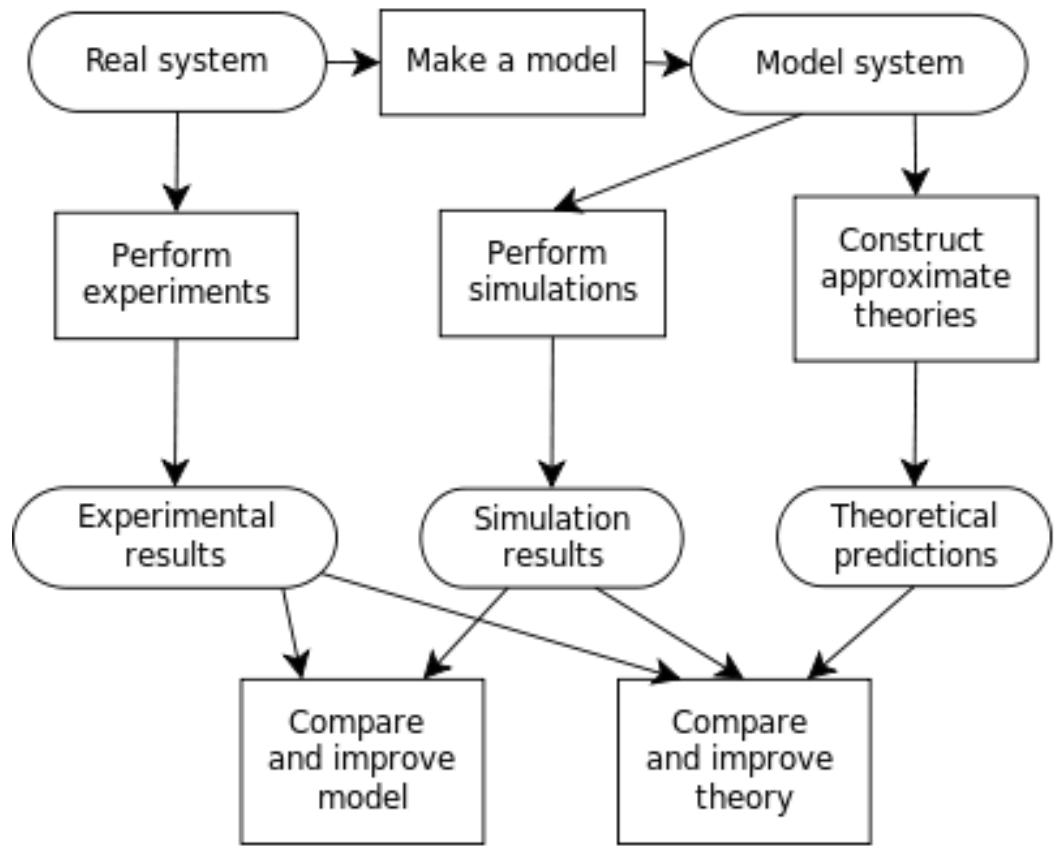

Figure 1: Process of building a computer model, and the interplay between experiment, simulation, and theory [11].

At the 9th International Conference on Sustainability in Energy and Buildings, SEB-17, 5-7 July 2017, Chania, Crete, Greece, [4] presented CAE methods for plate heat exchanger design. In this conference, the authors admonished: To simulate a heat exchanger, it is necessary to create a model and a computational mesh and then use a Computational Fluid Dynamics (CFD) software. When assembling the heat exchanger, [4] reports, complicated and irregular narrow channels are created. These channels are split into small volumes (elements). The final meshes are structured or unstructured with different element sizes.

At the International Conference on Knowledge Based and Intelligent Information and Engineering Systems, KES2017, 6-8 September 2017, Marseille, France, [5] presented Numerical Analysis and Improvement of the Heat Exchanger Designed For CoGenerating Units. In this study, Research on heat exchangers for the co-generating units was carried to obtain the optimum design, by comparing the efficiency and concepts used by different heat exchangers. The system was designed based on three basic parameters optimization: number of coolant tubes, diameter of the coolant tube and inlet velocity of the cold gases. These three variables were manipulated in order to investigate heat transfer performances, as well as, effects of heat transfer fluids and the system's efficiency. Simulations using Computational Fluid Dynamic (CFD) were carried out, to have a better understanding and distinct visualization of the fluid flow, and to test and compare the results. The outcomes show that, different size of coolant tube diameter has the biggest impact on the system efficiency, compared to the other two variables. Design improvement, based on the contributions of the key parameters to efficiency of the heat exchanger, is recommended, as a final outcome of the project conducted.

\subsection{Results:}

Resultant forces: reaction forces was analyzed for the entire model with the sum of forces along the X-axis, Sum X as 0.24691, while for the sum of the forces along the $\mathrm{Y}$ axis, Sum $\mathrm{Y}$ is -18.9449 . For the sum of forces along the $\mathrm{Z}$ axis, Sum $\mathrm{Z}$ is 0.0289852 and the resultant forces is 18.9465 . However, reaction moments were not carried out for the entire model, the reason being that the heat exchanger was presumed to be stationed or fixed at a point; consequently the entire model with the sum of forces along the $\mathrm{X}$-axis, Sum $\mathrm{X}$ as 0 , while for the sum of the forces along the $\mathrm{Y}$ axis, Sum $\mathrm{Y}$ is 0 . For the sum of forces along the $\mathrm{Z}$ axis, Sum $\mathrm{Z}$ is 0 and the resultant force is 0 .

Maximum fluid carrying capacity of the Heat Exchanger $=0.04 \mathrm{~m}^{3}$

Fluid used= Water

Density of Fluid $=997 \mathrm{~kg} / \mathrm{m}^{3}$

Mass of the Fluid $=$ Density of fluid $\mathrm{x}$ Volume $=997 \times 0.04=39.88 \mathrm{~kg}$

Weight of Fluid $=39.88 \times 10=398.8 \mathrm{~N}$

Total Weight used in this Simulation = Total Weight of components inside the HE +Weight of Maximum fluid carrying capacity $=2282.1+298.9=2680.9 \mathrm{~N}$ 
International Journal of Advances in Scientific Research and Engineering (ijasre), Vol 5 (2), February-2019

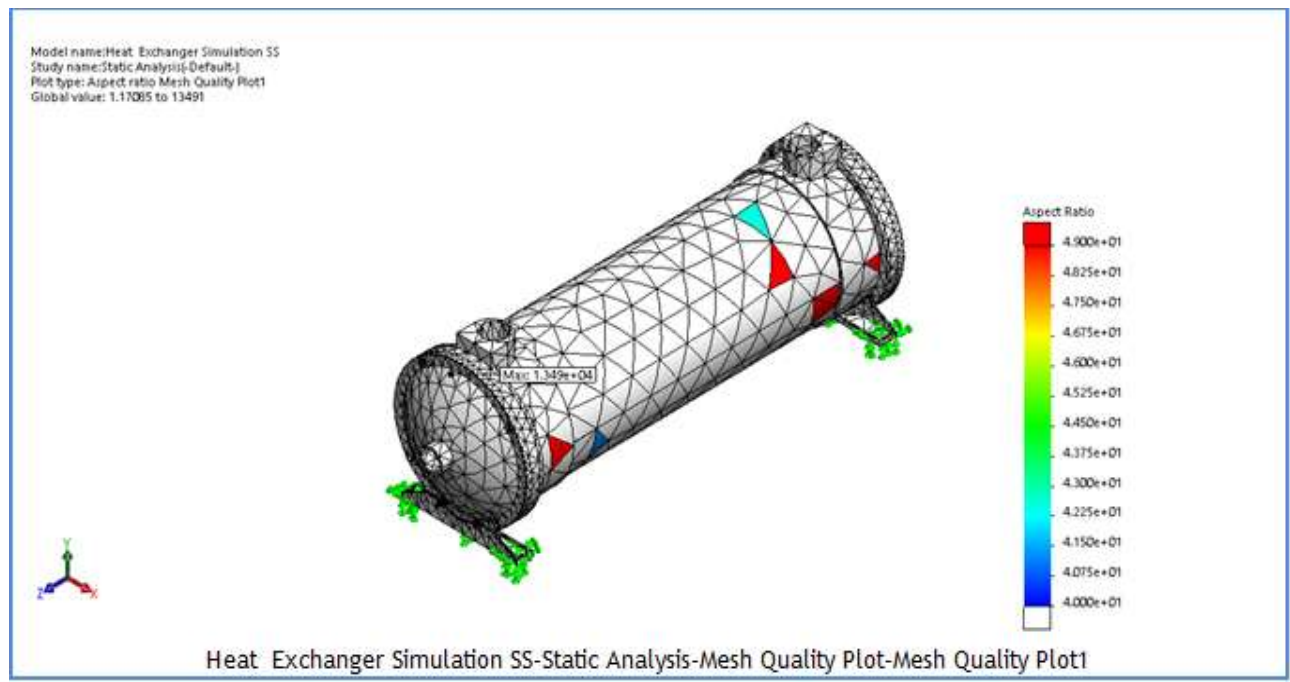

Figure 2: heat exchanger simulation SS-Analysis-Mesh Quality Plot-Mesh Quality Plot

The finite element mesh (figure 2) was used to subdivide the computer aided design model of the heat exchanger into smaller smaller domains called elements, over which a set of equations are solved. To greater extent, the accuracy that can be obtained from any FEA model is directly related to the finite element mesh used [15]-[17].

\section{Study Results}

\begin{tabular}{|c|c|c|c|}
\hline Name & Type & Min & Max \\
\hline Stress1 & VUN: von Mises Stress & $\begin{array}{l}0.000 \mathrm{e}+00 \mathrm{~N} / \mathrm{m}^{2} 2 \\
\text { Node: } 1654\end{array}$ & $\begin{array}{l}1.254 \mathrm{e}+0 \mathrm{~b} \mathrm{~N} / \mathrm{m} / 2 \\
\text { Node: } 38\end{array}$ \\
\hline & $\begin{array}{l}\text { sititionst } \\
\text { sist }\end{array}$ & & 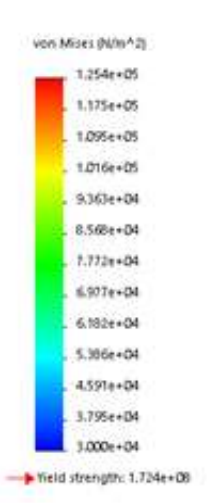 \\
\hline & leat Exchanger Simula & Analysis-Stress-Stre & \\
\hline
\end{tabular}

Figure 3: heat exchanger simulation SS-Static Analysis-Stress-Stress

From the study (figure 2), the von mises stress analysis showed $0 \mathrm{~N} / \mathrm{m}^{2}$ for minimum at node 1654 and 1.245 e 05 for N/m² maximum at node 38 .

Table 2: heat exchanger study properties 
International Journal of Advances in Scientific Research and Engineering (ijasre), Vol 5 (2), February-2019

\begin{tabular}{|c|c|}
\hline Stubly neme & STatie Nodinoth \\
\hline Anshris type & अanic \\
\hline Wesh the & Sald wewh \\
\hline Thermal thent: & on \\
\hline Thermal eptian & 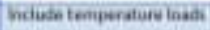 \\
\hline Lere wrsin tempermurn & 26 Knivin \\
\hline 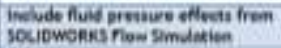 & on \\
\hline Selver type & Whin \\
\hline Iretent Effeat & on \\
\hline Seft lpives & of \\
\hline Imencivetief: & ant \\
\hline incameanibis banding spthan & watimate \\
\hline Leverabepinement & air \\
\hline Compuse free bedy foreet & on \\
\hline Fietien & oir \\
\hline Une Adaphive Method: & ait \\
\hline
\end{tabular}

Table 3: Mesh information

\begin{tabular}{|c|c|}
\hline Wesherese & Soliallow \\
\hline Mesher Uned: & Hended carvaturs basod mech \\
\hline Jeoblim sointi & 4hiteas \\
\hline haximum element ina & 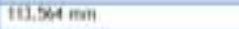 \\
\hline Winimun element tise & Z.R. \\
\hline Mesh Qunity Plet & Hon \\
\hline 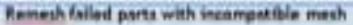 & or \\
\hline
\end{tabular}

Table 4: mesh quality plot

\begin{tabular}{|c|c|c|c|}
\hline Name & Type & Win & Max. \\
\hline 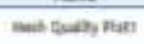 & Mpise & listeren & $\begin{array}{l}\text { Linesh } \\
\text { pinet ing }\end{array}$ \\
\hline
\end{tabular}

Table 5: resultant forces

Resultant Forces

Reaction forces

\begin{tabular}{|l|l|l|l|l|l|}
\hline Selection set & Units & Surn X & Sum Y & Sum Z & Resultant \\
\hline Entire Model & N & 0.24691 & 18.9449 & 0.0289652 & 18.9455 \\
\hline
\end{tabular}

Reaction Moments

\begin{tabular}{|l|l|l|l|l|l|}
\hline Selection set & Units & Sum X & Sum Y & Sum Z & Resultant \\
\hline Entire Modei & R,m & 0 & 0 & 0 & 0 \\
\hline
\end{tabular}

\begin{tabular}{|c|c|c|c|}
\hline Name & Type & Min & Max \\
\hline Displacement1 & URES: Resultant Displacement & $\begin{array}{l}0.000 \mathrm{e}+00 \mathrm{~mm} \\
\text { Node: } 44\end{array}$ & $\begin{array}{l}5.800 \mathrm{e}-05 \mathrm{~mm} \\
\text { Node: } 10589\end{array}$ \\
\hline 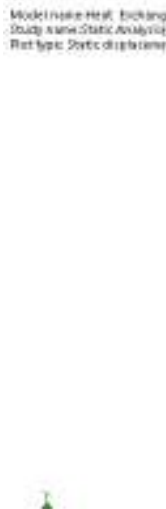 & 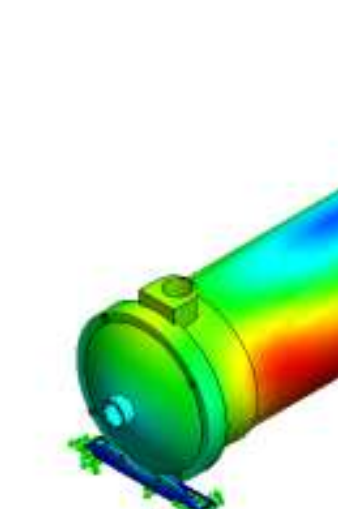 & . & 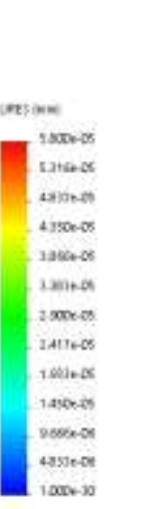 \\
\hline
\end{tabular}


International Journal of Advances in Scientific Research and Engineering (ijasre), Vol 5 (2), February-2019

Figure 4: Heat exchanger simulation SS- Static Analysis-Displacement-Displacement

From the study (figure 4) also, the resultant displacement analysis showed a maximum stress $5.800 \mathrm{e}-05$ mm at node 10589 and a minimum stress of $0 \mathrm{~mm}$ at node 44 .

\begin{tabular}{|l|l|l|l|}
\hline Name & Type & Min & Max \\
\hline Strain1 & ESTRN: Equivalent Strain & $\begin{array}{l}2.057 \mathrm{e}-11 \\
\text { Element: 802 }\end{array}$ & $\begin{array}{l}2.710 \mathrm{e}-07 \\
\text { Element: 2003 }\end{array}$ \\
\hline & & \\
\hline
\end{tabular}

Figure 5: Heat exchanger simulation SS-Static Analysis-Strain-Strain

From the study (figure 5), the equivalent strain analysis showed a minimum stress of 2.057e-11 at node 802 and a maximum stress of $2.710 \mathrm{e}-07$ at node 2003 .

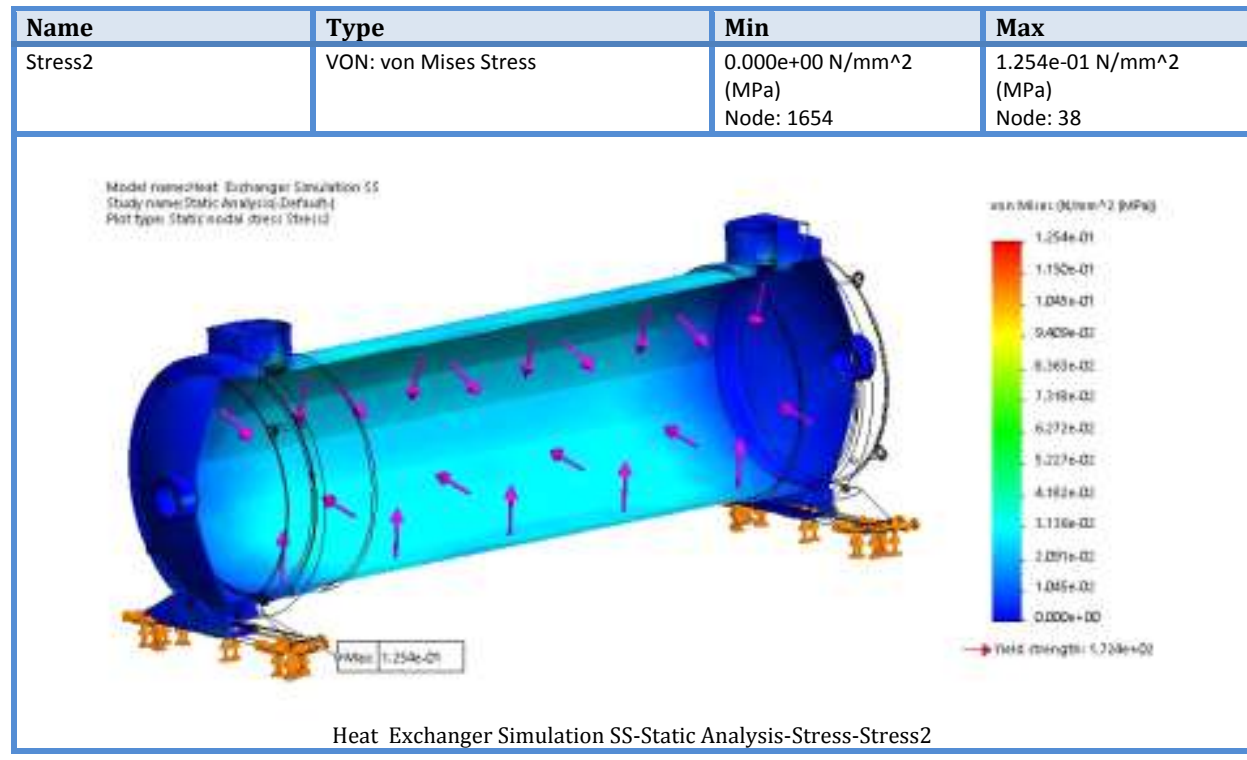

Figure 6: heat exchanger simulation SS-Static Analysis-Static Analysis-Stress-Stress2

From the study (figure 6), the von Mises stress analysis showed a minimum stress of $0 \mathrm{~N} / \mathrm{mm}^{2}$ at node 1654 and a maximum stress of $1254 \mathrm{e}-01 \mathrm{~N} / \mathrm{mm}^{2}$ at 38 . 


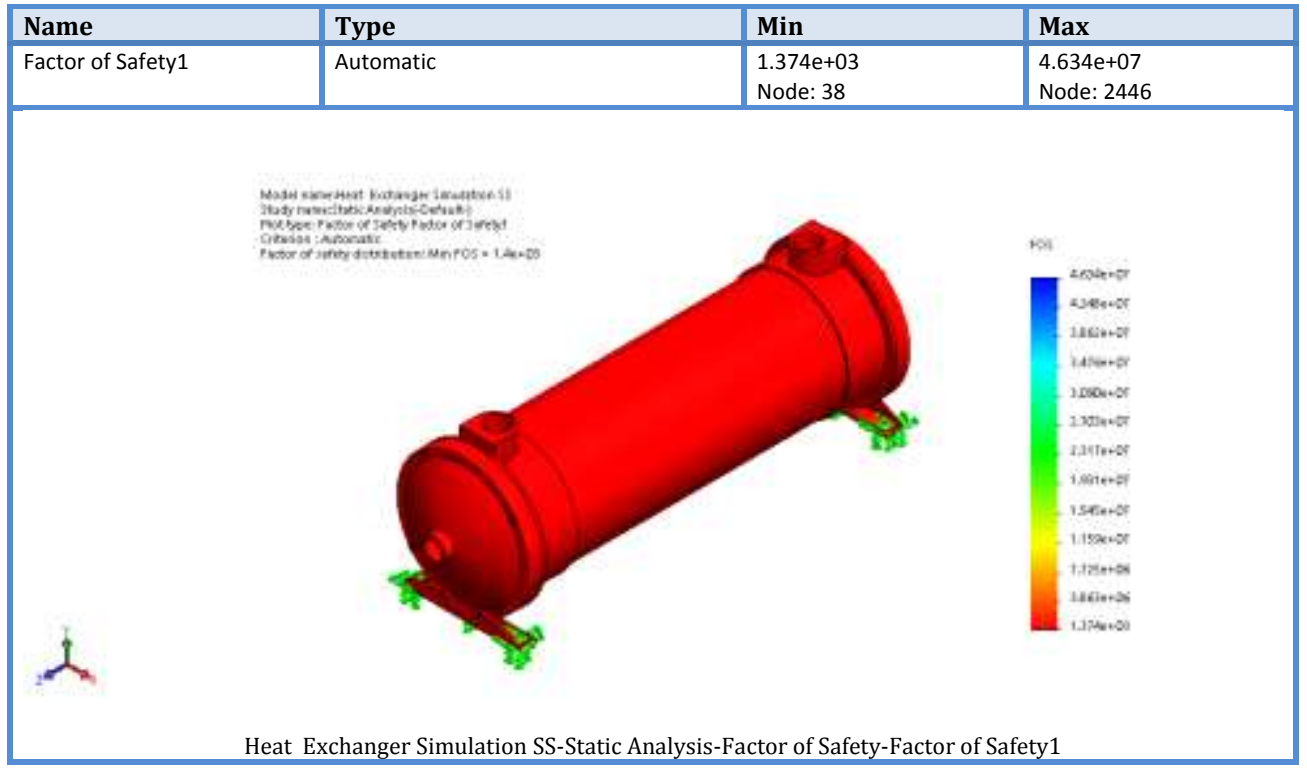

Figure 7: Heat exchanger simulation SS-Static Analysis-Factor of safety1

The final purpose of any analysis is to allow the comparison of the tensions, deformations and deviations developed with those allowed by the design criteria. Obviously, all structures, and their components, must be designed to have a capacity greater than what is expected to develop during the use of the structure to avoid failures. The tension calculated to develop in a member is compared to the strength of the material with which the composition is manufactured by calculating the ratio between the strength of the material and the calculated resistance. The ratio must obviously be greater than 1.0 if the member should not fail. However, the relationship between the allowable voltage and the developed voltage must be greater than 1.0 as a factor of safety (design factor) will be specified in the design requirement of the structure. All structures are designed to overcome the load that these structures are expected to experience during their use. The design factor (a number greater than 1.0) represents the degree of uncertainty in the value of the loads, the strength of the material and the consequences of the failure. The tension (or load, or deflection) that the structure is expected to experience is known as the work, the design or the limit voltage. The limit voltage, for example, is chosen to be a fraction of the elastic resistance of the material from which the structure is made. The relationship between the final strength of the material and the permitted voltage is defined as the safety factor against the final failure. The purpose of maintaining a safety factor in the elastic resistance is to prevent damaging deformations that would damage the use of the structure. [22]. From the results of the analysis (figure 7), the simulation shows a minimum of $1.374 \mathrm{e}+08$ at node 38 and maximum $4.634 \mathrm{e}+07$ at node 2446 .

\subsection{Conclusion:}

The maximum Stress experienced by the Heat Exchanger according to the simulation result is $1.254 \mathrm{e}-01 \mathrm{~N} / \mathrm{mm}^{2}$ (MPa) which is far less than the yield strength of the material used in building it $\left(1.72369 \mathrm{e}+08 \mathrm{~N} / \mathrm{m}^{2}\right)$. Hence the Heat Exchanger will survive the maximum loading and working capacity according to von Mises Stress analysis and with a significant factor of safety. For the mesh information: Mesh type is solid, while mesher used is blended curvature based mesh. Jacobian point is 4. Maximum element size is $113.564 \mathrm{~mm}$, minimum element size is $22.7129 \mathrm{~mm}$, mesh quality plot is high. For the mesh quality plot, minimum is $1.171 \mathrm{e}+00$ at element 2033. Maximum is $1.349 \mathrm{e}+04$ at element 1577. Resultant forces: reaction forces was analyzed for the entire model with the sum of forces along the $\mathrm{X}$-axis, Sum $\mathrm{X}$ as 0.24691 , while for the sum of the forces along the $\mathrm{Y}$ axis, Sum $\mathrm{Y}$ is 18.9449. For the sum of forces along the $\mathrm{Z}$ axis, Sum $\mathrm{Z}$ is 0.0289852 and the resultant forces is 18.9465 . However, reaction moments were not carried out for the entire model, the reason being that the heat exchanger was presumed to be stationed or fixed at a point; consequently the entire model with the sum of forces along the X-axis, Sum X as 0 , while for the sum of the forces along the $\mathrm{Y}$ axis, Sum $\mathrm{Y}$ is 0 . For the sum of forces along the $\mathrm{Z}$ axis, Sum $\mathrm{Z}$ is 0 and the resultant force is 0 .

\section{REFERENCES}

[1] Mohammad Reza Salimpour, Ahmed T. Al-Sammarraie, Azadeh Forouzandeh and Mahsa Farzaneh (2018), multi-layer circular microchannel heat sink construction design, ASME Journal of Thermal Science and Engineering Applications, 
[2] https://en.wikipedia.org/wiki/Heat_exchanger

[3] A. C. Mueller, (2019) Multimedia edition of the heat exchanger design manual, Begell House, Inc.

[4] Václav Dvořáka *, Tomáš Víta (2017), CAE methods for the design of plate heat exchangers, the 9th International Conference on Sustainability in Energy and Buildings, SEB-17, 5-7 July 2017, Chania, Crete, Greece, Energy Procedures 134 (2017) 234-243

[5] Firas B. Ismail, Marwan Ali, Milan Simic, SS TEOa, Numerical analysis and heat exchanger improvement designed for cogeneration units, International conference on smart and knowledge-based intelligent information and engineering systems, KES2017 , 6-8 September 2017, Marseille, France Proceia Computer Science 112 (2017) 2240-2248

[6] J. Lambert, L. Gosselin, Sensitivity analysis of the heat exchanger design before correlation uncertainties, Applied thermal engineering (2018), doi:

https://doi.org/10.1016/j.applthermaleng.2018.03.037

[7] Fuyu Liu, Jiaze Ma, Xiao Feng, Yufei Wang, simultaneous integrated design for the network of heat exchangers and cooling water system, Applied Thermal Engineering 128 (2018) 1510-1519

[8] K.H. Chew, J.J. Klemeš, S.R. Wan Alwi, Z.A. Manan, process modifications to maximize energy savings in total heat integration of the site, Appl. Therm. Ing. 78 (2015) 731-739.

[9] K.H. Chew, J.J. Klemeš, S.R. Wan Alwi, Z.A. Manan, modification of the process of the total heat integration profile of the site for the reduction of capital costs, Appl. Therm. Ing. 89 (2015) 1023-1032.

[10] Jurandir Primo, PE, PDHonline Course M371 (2 PDH), shell and tube heat exchangers

Basic calculations, 2012

[11] https://en.wikipedia.org/wiki/Computer_simulation

[12] Fuqiang Gaoa, Peter K. Kaiser, Doug Stead, Erik Eberhardt, Davide Elmo, numerical simulation of stress bursts using a novel initiation method, Computers and Geotechnics 106 (2019) 117-127

[13] Strogatz, Steven (2007). "The end of the insight". In Brockman, John. What is your dangerous idea? HarperCollins. ISBN 9780061214950

[14] Fábio A.S. Mota, E.P. Carvalho and Mauro A.S.S. Ravagnani (2018), Modeling and Design of Plate Heat Exchangers, Chapter Seven, INTECH open science, http://dx.doi.org/10.5772/60885

[15] Comsol Multiphysics Cyclopedia, 2019

[16] Yucheng Liu and Gary Glass (2013), Effects of Mesh Density on Finite Element Analysis, SAE International

[17] Arash Ramezani and Hendrik Rothe (2016), influences of meshing and High-Performance Computing towards Advancing the Numerical Analysis of High-Velocity Impacts, International Journal on Advances in Systems and Measurements, vol. 9, no. 3 \&4.

[18] DassaultSysteme (2018) TUTORIALS SOLIDWORKS FLOW SIMULATION 2018

[19] seacad_admin (2016) Improving the design of a heat exchanger using SOLIDWOrkS Flow Simulation, https://seacadtech.com/improving-the-design-of-a-heat-exchanger-using-solidworks-flow-simulation/

[20] Simulation of SOLIDWORKS - Heat Exchangers, https://www.solidsolutions.co.uk/solidworks/tutorial-videos/solidworkssimulation-heat-exchangers.aspx

[21] NPTEL-Process Design of Heat Exchanger, https://nptel.ac.in/courses/103103027/pdf/mod1.pdf

[22] https://en.wikipedia.org/wiki/Stress\%E2\%80\%93strain_analysis 
International Journal of Advances in Scientific Research and Engineering (ijasre), Vol 5 (2), February-2019

[23] Donald Ray Smith and Clifford Truesdell (1993) "An introduction to the mechanics of the continuum after Truesdell and Noll". Jumper. ISBN 0-7923-2454-4 